\title{
Effect of mat design and manufacturing parameters on the mechanical properties of needle-punched flax fiber-reinforced composites.
}

\author{
Md. Shadhin ${ }^{1,2}$, Raghavan Jayaraman ${ }^{1}$, Mashiur Rahman ${ }^{1,2}$ \\ ${ }^{1}$ Composite Materials and Structures Research Group and Department of Mechanical Engineering \\ ${ }^{2}$ Department of Biosystems Engineering \\ University of Manitoba, Winnipeg, MB R3T5V6, Canada \\ shadhinm@myumanitoba.ca, Raghavan.Jayaraman@umanitoba.ca, Mashiur.Rahman@umanitoba.ca
}

\begin{abstract}
Flax is one of the natural fibers currently pursued as a renewable source to replace glass fibers in polymer composites. Vacuum Assisted Resin Transfer Molding (VARTM), used to manufacture medium to large sized composites for transportation industries, require non-woven mats. The manufacturing (permeability) and structural (volume fraction $\left(\mathrm{V}_{\mathrm{f}}\right)$, and thickness) requirements for the non-woven mats used in VARTM process, should be met. Unlike glass, flax mats are neither optimized, to yield desired permeability for easy impregnation, compaction, final part thickness, fiber volume fraction, and properties, nor are commercially manufactured in North America. Developing this knowledge is the focus of this study. Effect of needle punch density on flax fiber mat structure (areal density, $\mathrm{V}_{\mathrm{f}}$, thickness, and permeability) and the effect of consolidation pressure while manufacturing composites on its structure $\left(\mathrm{V}_{\mathrm{f}}\right.$, part thickness) and properties was studied. The tensile strength and tensile modulus of needle-punched flax composites, manufactured using VARTM pressure as well as compression molding pressures (subsequent to VARTM molding), were measured and used in evaluating the effect of various parameters identified above. Mats manufactured with 20,30 , and 72 punches $/ \mathrm{cm}^{2}$ needle punch density were used. The permeability decreased with increase in the punch density. The consolidation of, fiber volume fraction in, and properties of composites manufactured using mat with loosely bound (72 P with 2 $\mathrm{mm}$ needle punch depth) fibers were higher than the tightly bound mats (20P and 30P with $8 \mathrm{~mm}$ needle punch depth).
\end{abstract}

Keywords: Flax fiber composite, Needle-punch density, VARTM, Compression molding, Mechanical properties.

\section{INTRODUCTION}

The natural fibers, such as flax, kenaf, jute, hemp, and sisal are increasingly investigated as an environmental friendly alternative to glass fibers for engineering applications [1-7].
Non-woven glass mats, used in manufacturing composite parts using VARTM (Vacuum Assisted Resin Transfer Molding), have been designed to yield good impregnation and optimal properties. The mat parameters that should be optimized are mat areal density and thickness, which in turn affects the permeability and ease of resin impregnation, consolidation under VARTM pressure, final $V_{f}$ and properties. Unlike binders used in binding the glass fibers in glass mat, the natural fiber mats have to be bound together by needle punching, the effect of this on mat density and thickness is unknown.

Published studies on natural fiber mat design and its effect of manufacturing and properties of natural fiber reinforced composites are limited. Niu et al. [8] investigated the effect of operating parameters like carding method involved during manufacturing of nonwoven flax mat on the mechanical properties of flax composite. However, they did not study the effect of needle punch density. Mahi [5] studied in detail the effect of mat manufacturing parameters on manufacturing and properties of hemp fiber composites manufactured through VARTM and compression molding. The permeability of hemp mat and tensile modulus of hemp fiber composite were both found to be a function of fiber volume fraction and mat punch density. The permeability of the mat decreased with increase in punch density and the tensile modulus increased with the increase in punch density at a given consolidation pressure [5].

Similar studies on flax mat design and its relationship to composite manufacturing and mechanical properties of composites are lacking. Hence, the main objective of this study is to generate this knowledge. The effect of density of needle punches, used to bind the fibers together, on mat permeability, consolidation, and final fiber volume fraction was studied and used with the mechanical properties to understand the effect of mat punch density on properties of flax fiber composites. 


\section{EXPERIMENTAL DETAILS}

\section{A. Materials, Manufacturing, and Testing}

Flax mats, manufactured by Composite Materials and Structures Research Group at the University of Manitoba, was used in this study. The mats were manufactured using locally grown flax fibers and the pilot plant at North Carolina State University, USA. The needle punch density was varied between 20 and 72 needles per inch and the needle punch depth was varied between 2 and $8 \mathrm{~mm}$. These flax mats were used along with unsaturated polyester resin (STYPOL 8084) to manufacture flax fiber composites at room temperature using VARTM. 2 weight \% (w/w) of LUPEROX $224(2,4-$ Pentanedione peroxide) was used as the curing initiator. After impregnation, the impregnated plates were allowed to cure at room temperature and VARTM pressure for 24 hours. Additional panels, after impregnation at VARTM pressure, were removed from the VARTM mold, and cured under compression molding pressures at room temperature using G50 H- 24-CLX hydraulic press manufactured by WABASH MPI, IN, USA. The pressures used in compression molding were $260 \mathrm{kPa}$ and $560 \mathrm{kPa}$. The compression pressure was varied to study the compaction behavior and to vary the fiber volume fraction.

The permeability of the mat was measured using Fraizer Permeability tester. Circular mat specimens of $14 \mathrm{~cm}$ diameter were cut from the mat roll at random locations and used in the measurement. Red oil was used in the permeability measurement and the viscosity of red oil was determined using Brookfield LVDV-E Viscometer. The rate of oil flow through the mat and the pressure difference across the mat thickness were measured and used in equation [1] to determine the permeability.

$$
\mathrm{k}=\mathrm{Q} \eta \mathrm{L} / \mathrm{A} \Delta \mathrm{P}
$$

where, $\mathrm{k}=$ Mat permeability,

$\mathrm{Q}=$ volumetric flow rate,

$\eta=$ viscosity of red oil $(5.57 \mathrm{cP})$

$\mathrm{A}=$ Area of the specimen perpendicular to flow direction

$\Delta \mathrm{P}=$ Pressure difference

$\mathrm{L}=$ Mat thickness
The flax mat composite panels were bonded with $20 \mathrm{~mm}$ wide tabs to prevent the crushing of the gripped ends during tensile testing. Tabs cut from carbon fiber epoxy composite laminates were bonded to the edges of the flax-polyester composite panels using room temperature curing adhesive. Composite test specimens, $127 \mathrm{~mm}$ in length and $20 \mathrm{~mm}$ in width were cut from these panels using Micro-Matic Precision Wafering Machine manufactured by MICROMECH MFG. CORP. Edges of the prepared testing coupons were ground using silicon carbide papers and polished further using alumina powder to remove any damage due to cutting. The length of the tabbed end was 38 $\mathrm{mm}$.

The fiber volume fraction in the composite was measured using Helium Pycnometer (Model \# UPY-32, UPY-32T; v 5.04 manufactured by Quantachrome INSTRUMENTS).

The tensile properties of flax-reinforced composite were determined using MTS testing machine (Model \# 820-030SL manufactured by MTS Systems Corporation) fitted with a $30 \mathrm{kN}$ load cell as per ASTM D3039. The testing was done at a cross-head speed of $2 \mathrm{~mm} / \mathrm{min}$. The strain was measured using an extensometer with $50.8 \mathrm{~mm}$ gage length. Five samples were tested for each punch density and consolidation pressure. The tensile modulus was determined in the strain range of $0.1 \%$.

\section{RESULTS AND DISCUSSION}

\section{A. Physical properties of nonwoven flax mat}

The physical properties of needle punched nonwoven flax mat are tabulated in Table I. The large standard deviation in the areal density of the mat points to large variation in the areal density from one location to another location of the mat. Given the similar areal density with large standard deviation, increasing the punch density from 20 to 30 did not change the mat thickness. The higher mat thickness for 72 punches $/ \mathrm{cm}^{2}$ mat when compared to 20 and 30 is believed to be due to higher starting areal density of the flax fiber web (before needle punching) and smaller needle depth. This trend is also observed in the fiber volume fraction of the mat; instead of increasing, the fiber volume fraction in the mat decreased with punch density.

TABLE I. PHYSICAL PROPERTIES OF MANUFACTURED NEEDLE PUNCHED NONWOVEN FLAX MAT.

\begin{tabular}{|c|c|c|c|c|c|c|}
\hline $\begin{array}{c}\text { Flax } \\
\text { mat }\end{array}$ & $\begin{array}{l}\text { Punch } \\
\text { density } \\
\left(\mathbf{p} / \mathbf{c m}^{2}\right)\end{array}$ & $\begin{array}{c}\text { Needle } \\
\text { penetration } \\
\text { depth }(\mathrm{mm})\end{array}$ & 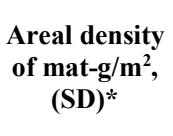 & $\begin{array}{c}\text { Mat thickness } \\
\text { before } \\
\text { consolidation } \\
\text { (mm), (SD)* }\end{array}$ & $\begin{array}{l}\text { Fiber volume } \\
\text { fraction in } \\
\text { mat, } V_{f} \%, \\
\text { (SD)* }\end{array}$ & $\begin{array}{c}\text { Transverse Mat } \\
\text { Permeability x 10-12 } \\
\left(\mathrm{m}^{2}\right),(\mathrm{SD}) *\end{array}$ \\
\hline 20-P & 20 & 8 & $814.7(88.3)$ & $4.6(0.3)$ & $11.6(0.7)$ & $9.4(3.4)$ \\
\hline 30-P & 30 & 8 & $823.6(97.4)$ & $4.7(0.5)$ & $11.4(1.4)$ & $8.7(3.4)$ \\
\hline 72-P & 72 & 2 & $885.2(108.5)$ & $6.8(0.4)$ & $8.7(1.4)$ & $6.9(3.5)$ \\
\hline
\end{tabular}


TABLE II. PHYSICAL PROPERTIES OF NEEDLE PUNCHED NONWOVEN HEMP MAT [5].

\begin{tabular}{|c|c|c|c|c|c|}
\hline $\begin{array}{c}\text { Hemp } \\
\text { mat }\end{array}$ & $\begin{array}{l}\text { Punch } \\
\text { density } \\
\left(\mathbf{p} / \mathrm{cm}^{2}\right)\end{array}$ & $\begin{array}{l}\text { Areal density of } \\
\text { mat-g/m } \mathbf{m}^{2} \text {, (SD)* }\end{array}$ & $\begin{array}{c}\text { Mat thickness } \\
\text { before } \\
\text { consolidation } \\
(\mathrm{mm}),(\mathrm{SD})^{*}\end{array}$ & $\begin{array}{c}\text { Fiber volume } \\
\text { fraction in mat, } \\
\mathbf{V}_{\mathrm{f}} \%,(\mathrm{SD})^{*}\end{array}$ & $\begin{array}{c}\text { Hemp mat Transverse } \\
\text { Permeability } \times 10^{-7}\left(\mathrm{~m}^{2}\right) \text {, } \\
\text { (SD)** }\end{array}$ \\
\hline 20-P & 20 & $1014.8(7) *$ & $5.75(0.9)$ & $11(3.5)$ & - \\
\hline $30-\mathrm{P}$ & 30 & $1113.9(6.6)$ & $5.39(1.2)$ & $15(1.1)$ & $2.8(0.5)$ \\
\hline 70-P & 70 & $1241.3(11.2)$ & $6.83(1.4)$ & $12(1.5)$ & $0.6(0.04)$ \\
\hline
\end{tabular}

The transverse permeability of the flax mat decreased with increase in punch density as shown in Figure 1. These permeability values are substantially lower than those for needle punched hemp mat [5] listed in Table II. This is believed to be due to dense flax mats, smaller flax fiber diameter, and shorter flax fibers when compared to hemp fibers.

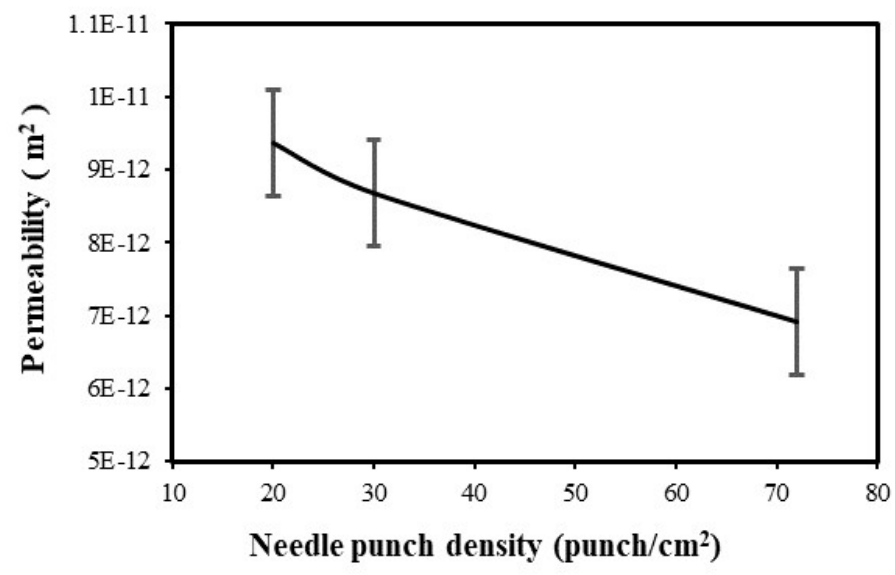

Figure 1. Effect of needle punch density on the transverse permeability of flax mat.

\section{B. Effect of consolidation pressure on final part thickness and fiber volume fraction of flax-reinforced composite}

The consolidation pressure used in VARTM and compression molding had significant influence on the final part thickness and fiber volume fraction of composites manufactured using various flax mats. The thickness of cured plates is plotted as a function of molding pressures in Figure 2. The increase in consolidation, indicated by the decrease in thickness, is highest when the pressure was increased from $101 \mathrm{kPa}$ to $260 \mathrm{kPa}$ and the increase was relatively gradual when the pressure was increased to 560 $\mathrm{kPa}$. Moreover, maximum consolidation was observed for 72 punches $/ \mathrm{cm}^{2}$, which is believed to be due to relatively loosely held fiber mat, higher starting areal density, and shorter needle depth. The consolidation in 20-P and 30-P composites were similar.

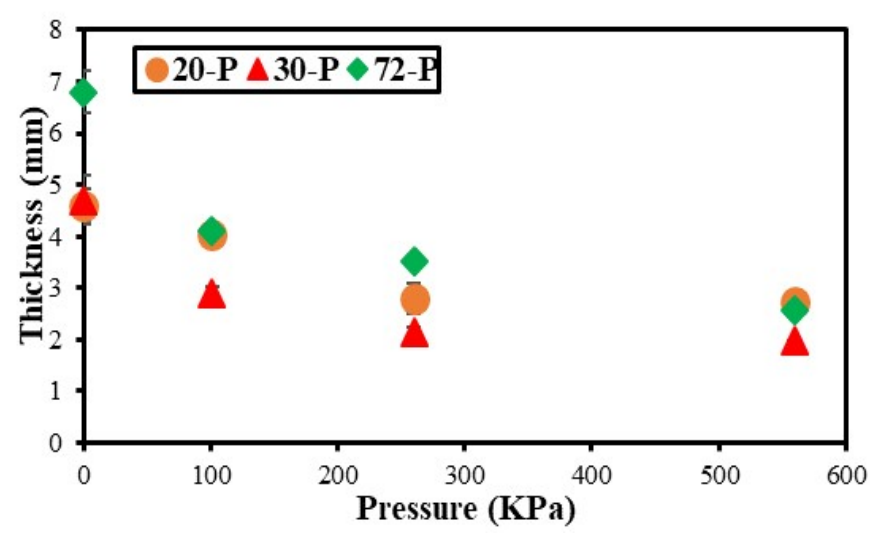

Figure 2. Effect of consolidation pressure on composite thickness during manufacturing.

The fiber volume fraction in the composites is plotted in Figure 3 as a function of compaction pressure for various needle punched flax mat composites. The fiber volume fraction increased with consolidation pressure. The rate of increase was higher until $260 \mathrm{kPa}$ compared to the increase when the pressure was increased from 260 to $560 \mathrm{kPa}$. This is to be expected since the pressure required to compress the fiber bed would increase as the compaction increases. Due to relatively loose binding of fibers in 72-P mats, the increase in fiber volume fraction from 0 to $560 \mathrm{kPa}$ is more than that with $20-\mathrm{P}$ and $30-\mathrm{P}$ flax composites. At any consolidation pressure, the fiber volume fraction differed with punch density due to differences in starting fiber volume fraction $\%$ in the mat and in the consolidation behavior, with pressure applied during manufacturing.

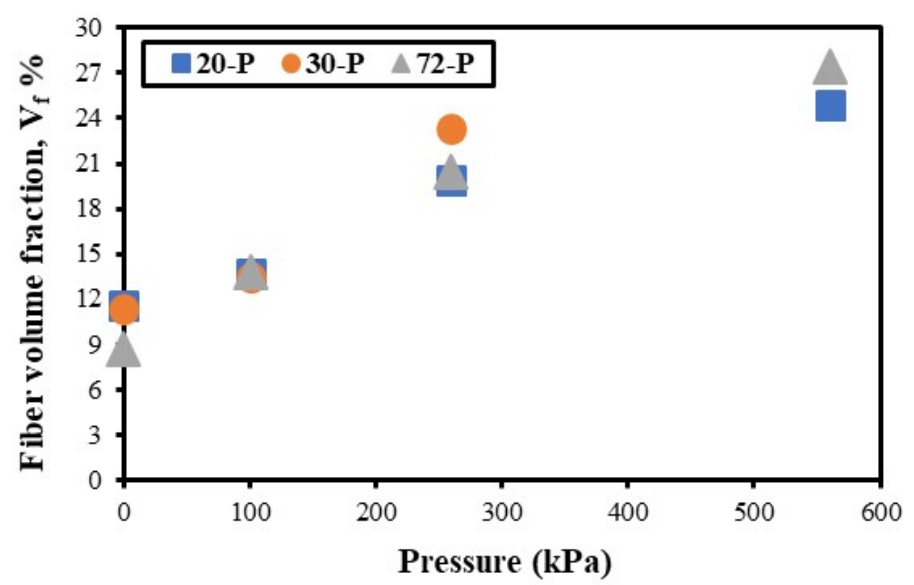

Figure 3. Effect of consolidation pressure on fiber volume fraction. 


\section{Effect of punch density on mechanical properties of needle punched flax composite}

The modulus and tensile strength for a given punch density increased with consolidation pressure as shown in Figure 4 and 5, respectively. For a given punch density, the properties increased with consolidation pressure due to increase in fiber volume fraction. However, for the same consolidation pressure, the properties varied with punch density due to difference in the fiber volume fraction caused by the difference in consolidation behavior.

While the properties varied marginally with the punch density at VARTM pressure, the variation was significant at higher pressures. 72-P mat resulted in the best properties at all pressures. This suggests that higher areal density mat with loosely bound fibers is preferred. The areal density would be limited by permeability required for successful consolidation.

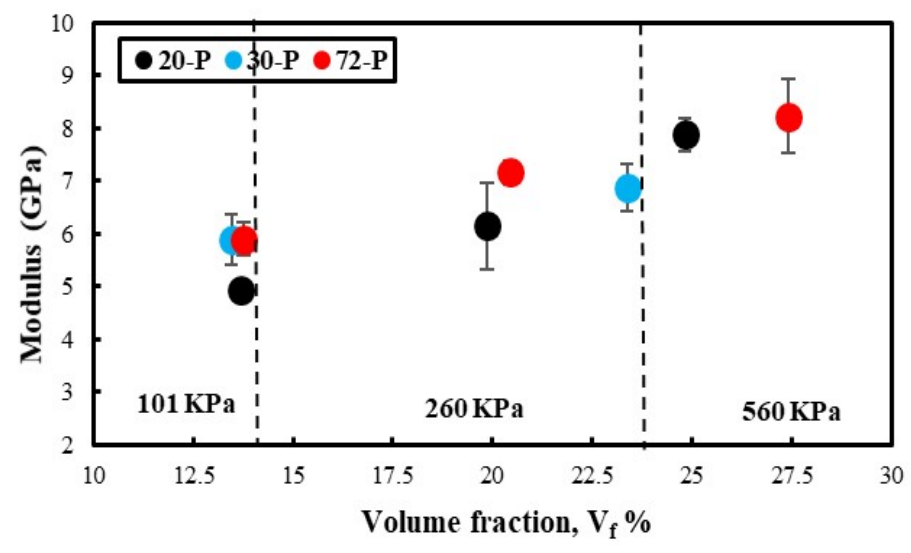

Figure 4. Relationship between tensile modulus and fiber volume fraction of flax-polyester composite for different punch density.

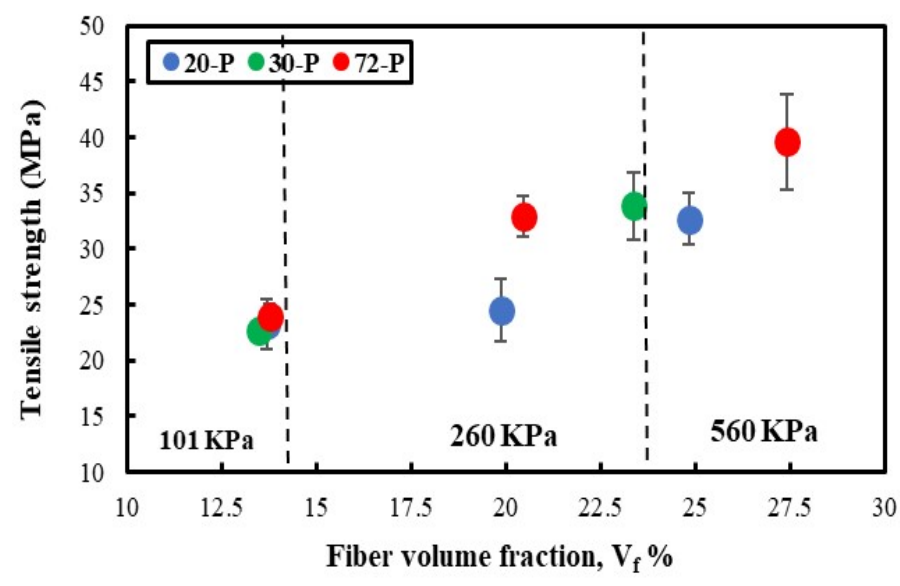

Figure 5. Relationship between tensile strength and fiber volume fraction of flax-polyester composite for different punch density.

\section{CONCLUSION}

The density of punches used in binding the flax fibers has a significant effect on the permeability, consolidation during manufacturing, and properties of flax fiber composites. The permeability decreased with increase in punch density. The consolidation of, fiber volume fraction in, and properties of composites manufactured using mat with loosely bound (72$\mathrm{P}$ with $2 \mathrm{~mm}$ needle punch depth) fibers were higher than the tightly bound mats (20-P and 30-P with $8 \mathrm{~mm}$ needle punch depth). Further research, using additional punch densities and needle depth, is required to identify the ranges of areal density, punch density, and punch depth that would be optimum for flax fiber mats used in VARTM and compression molding.

\section{REFERENCES}

[1] Wróbel, K., Magdalena, Magdalena, C., Anna, K., Magdalena, Ż., Jacek, K., Lucyna, D., Jerzy, H., Maciej, P. \& Jan, S. "New biocomposites based on bioplastic flax fibers and biodegradable polymers." Biotechnology progress, 5(2012): 1336-1346. doi:10.1002/btpr.1599.

[2] Yan, L., Nawawi, C. \& Krishnan, J. "Flax fibre and its composites-A review." Composites Part B:

Engineering 56(2014): 296-317.

doi.org/10.1016/j.compositesb.2013.08.014

[3] Nishino, T., Koichi, H., Masaru, K., Katsuhiko, N., \& Hiroshi, I. "Kenaf reinforced biodegradable composite." Composites science and technology, 9(2003): 1281-1286. doi:10.1016/S0266-3538(03)00099-X.

[4] Wambua, P., Jan, I. \& Ignaas, V. "Natural fibres: can they replace glass in fibre reinforced plastics?" Composites science and technology, 9(2003): 1259-1264. doi:10.1016/S0266-3538(03)00096-4.

[5] Fahimian, M., Jayaraman, R. "Processing-StructureProperty Relationship in Needle-Punched Nonwoven Natural Fiber Mat Composites." PhD diss., University of Manitoba, 2013. http://hdl.handle.net/1993/22207

[6] Karnani, R., Mohan, K. \& Ramani, N. "Biofiber-reinforced polypropylene composites." Polymer Engineering \& Science, 2(1997): 476-483. doi:10.1002/pen.11691.

[7] Oksman, K., Lennart, W., Lars, A. B., \& Romildo, D. T. F. "Morphology and mechanical properties of unidirectional sisal-epoxy composites." Journal of Applied Polymer Science, 13(2002): 2358-2365. doi.org/10.1002/app.10475

[8] Niu, H., Xiaoning, J., Rui, \& Hua, Z. "Direct manufacturing of flax fibers reinforced low melting point PET composites from nonwoven mats." Fibers and Polymers, 2(2010): 218-222. doi:10.1007/s12221-010-02182 